\title{
Exclusión versus inclusión: democratización y reforma económica en Centroamérica
}

\author{
NADiRf. DuráN* \\ LUIS ARMANDO GONZÁL.H***
}

\section{Planteamiento del problema}

A partir de la década de los años ochenta y noventa, sucedieron en Centroamérica una serie de cambios políticos y económicos de gran envergadura. En materia política, aunque con ritmos distintos en cada país, se fueron dando procesos de transición democrática, mediante los cuales, no sólo se abrieron los espacios para la competencia política -cuya expresión más llamativa son los continuados eventos electorales-, sino que también se crearon un conjunto de instituciones destinadas a ser el soporte de los ordenamientos democráticos que se deseaba construir.

Como se verá en su momento, la transición democrática en Centroamérica tuvo dos características bien propias: por un lado, se comenzó a generar en el marco de agudos conflictos militares en El Salvador, Guatemala y Nicaragua, así como de una militarización cre-

* Licenciada en Ciencias Juridicas por la UCA. Egresada de la Maestría en Ciencia Política de la UCA.

** Maestro en Ciencias Sociales por la FLACSO-México. Director del CIDAI de la $U C A$. 
ciente de la región en su conjunto, propiciada por el involucramiento de Estados Unidos en el conflicto regional; y, por otro lado, su avance y profundización dependía del fin de las hostilidades en cada país y de la desmilitarización del área, lo cual suponía un replanteamiento de la política exterior norteamericana hacia la región.

De aquí que la transición centroamericana no se completó, si no hasta que los conflictos militares fueron resueltos por acuerdos políticos internos -Acuerdos de Paz en El Salvador y Guatemala-, por acuerdos regionales - Contadora y Esquipulas - y hasta que Estados Unidos cedió a las presiones locales e internacionales a favor de una solución negociada a la crisis centroamericana. La democratización en Centroamérica es, pues, inseparable de los procesos de negociación encaminados a lograr la paz en la región. Esto, a diferencia de lo acontecido en América del Sur, donde el proceso de transición a la democracia, iniciado en la primera mitad de los años ochenta, consistió en lo fundamental en la reconstitución de las instituciones políticas - partidos, parlamentos y sistemas legales - violentadas por los regímenes militares y no en la superación de una situación de guerra abierta, como sucedió en Centroamérica ${ }^{1}$.

En materia económica, las décadas de los años ochenta y noventa fueron escenario de profundos cambios en las estructuras productivas centroamericanas. Mientras sus países se debatían en agudas crisis políticas, así como en el modo de resolverlas, los sectores agrícola e industrial estaban siendo desplazados, como ejes de acumulación, por el sector comercial y financiero; es decir, se estaba asistiendo a una "terciarización" de la economía, lo cual no era ajeno a los cambios que se estaban operando en la economía mundial durante esos años y que desembocarían en el capitalismo globalizado de las últimas dos décadas del siglo $\mathrm{XX}^{2}$. Pocos se percataron de las drásticas transformaciones que se estaban operando en la economía mundial; sólo unos cuantos cayeron en la cuenta del impacto de esos cambios en el carácter de las economías de la región. En su mayoría, las élites políticas e intelectuales estaban ocupadas en cómo terminar con la guerra, el terrorismo y la intervención norteamericana.

En la medida que el conflicto fue disminuyendo en intensidad -esto es, en la medida que se acercaba su solución por la vía negociada - los problemas económicos ocuparon su lugar en la agenda de los actores 
políticos y empresariales que, como resultado de las negociaciones de pacificación, lograron el acceso a puestos de primera importancia en la conducción de los Estados centroamericanos: los actores políticos y empresariales de derecha. En virtud de este hecho, la pacificación, a la vez que abrió las puertas a la posibilidad de democratizar los sistemas políticos, en la misma medida abrió las puertas a una gestión estatal que estaba llamada a convertirse en sostén de determinados grupos empresariales, para los cuales la democracia no era más que un aspecto más de la seguridad que ansiaban para expandir sus negocios. Para los grupos empresariales que despuntaban como los más importantes a inicios de la década de los años noventa, el orden democrático que se comenzaba a construir debería ser "su" orden democrático; es decir, debía ser, antes que otra cosa, un orden que les permitiera aumentar sus riquezas, en paz y tranquilidad, sin perturbaciones de ninguna naturaleza.

Los límites de la democracia, en este sentido, estaban definidos por los intereses de los grupos empresariales que, con sentido de oportunidad y habilidad, lograron articular esos intereses con los de quienes, desde puestos clave en el aparato del Estado, condujeron las negociaciones con la oposición armada hasta la finalización de los conflictos militares. La pacificación en Centroamérica dio lugar, pues, a dos caminos contradictorios, el uno hacia la política y el otro hacia la economía: el primero, apunta hacia la democratización política, con sus exigencias de inclusión social; el otro, hacia el predominio de una lógica empresarial voraz y excluyente. Por paradojas de la historia, la primera tuvo, entre sus principales gestores, a actores socio-políticos identificados casi plenamente con la segunda, a la que -a lo largo de la década de los noventa- buscaron favorecer, por todos los medios, desde las esferas estatales.

Los actores empresariales y sus representantes en el aparato político se hicieron cargo del impacto de los cambios de la economía globalizada en Centroamérica, pero no lo hicieron desde la óptica de los sectores económicos tradicionales o desde la mayor parte de la población, sino desde los emergentes sectores financiero y comercial, de cuyas demandas hicieron eco: la retirada del Estado del ámbito económico - lo cual pasaba por su "modernización" y "reforma"-, la privatización de los activos estatales con mayor potencial económico 
y el apoyo estatal para la inserción de los respectivos países en el bloque comerciales encabezado por Estados Unidos.

Cada una de estas demandas encontró eco en las administraciones de derecha o de centro derecha que fueron asumiendo la conducción estatal desde que se desmontaron los conflictos militares en El Salvador, Guatemala y Nicaragua y la paz llegó a Centroamérica. La reforma económica se decantó cada vez más hacia la privatización de las telecomunicaciones, la energía eléctrica, las pensiones de retiro y, en los últimos años, de los servicios de salud. Tras dos décadas de reforma económica, los grandes ganadores han sido los grupos y familias del sector financiero, mientras que los grandes perdedores han sido los sectores mayoritarios de la sociedad — cuyas condiciones de vida han empeorado-y las instituciones democráticas — violentadas permanentemente por los abusos y desidia de los grupos de poder económico-.

En suma, la democratización en Centroamérica se ba visto acompañada, paralelamente, de una serie de procesos de reforma económica - ajuste estructural, estabilización, privatización y medidas de apertura comercial-, asi como de redefinición de las funciones del Estado - concretada en su reforma y modernización - que han becho eco de las demandas de los grandes sectores empresariales, particularmente de los grupos de poder vinculados al comercio y a las finanzas. Como señala Fred Judson, "en el contexto del ajuste y la reestructuración, la democratización centroamericana presenta varios aspectos notables. Primero, las elecciones formales durante los noventa ha llevado al poder a gobiernos comprometidos con las agendas de los Programas de Ajuste Estructural. Asimismo, los Estados se han reestructurado conforme a los Programas de Ajuste Estructural; el proceso ha dejado a entidades, previamente descritas como 'Estados débiles', con opciones mucho más limitadas en el campo de la política pública, especialmente en lo que se refiere al régimen de la acumulación y a la distribución de la riqueza social producida bajo este régimen" ${ }^{\text {. }}$.

La democratización llegó a su punto más elevado cuando se firmaron los respectivos acuerdos de paz en El Salvador y Guatemala, cuando la "contra" nicaragüense se desmovilizó y cuando Estados Unidos retiró sus tropas de Honduras. Visto desde aquí, los países centroamericanos estaban listos para dar el paso siguiente: avanzar hacia la consolidación democrática ${ }^{+}$. Pero se había desarrollado un inmenso 
obstáculo para ello: los procesos de reforma económica y de desarticulación del Estado que se desarrollaron entre tanto, agudizaron los niveles de marginalidad social, exclusión y pobreza, al tiempo que alentaron tanto la desconfianza ciudadana en las instituciones como el rechazo social a cualquier forma de participación socio-política.

La paz llegó, pero no para quedarse, pues el funcionamiento del modelo económico diseñado la socavaba de raíz. Difícilmente, la paz y la democracia podrían cobrar vigencia plena mientras la exclusión social y la marginalidad fueran el subproducto necesario de la economía. Y, precisamente, era ese y no otro el sostén del modelo económico que se comenzó a construir a finales de la década de los años ochenta y a inicios de la década siguiente; hoy es ese el modelo que impone sus ritmos y sus exigencias a la sociedad y a la política.

De nueva cuenta, la economía puso límites infranqueables al avance de la democracia, poniendo de manifiesto que una economía excluyente y marginalizadora es la mayor traba para la democratización de las sociedades centroamericanas. Este es el dilema en el que está atrapada Centroamérica en el momento actual. La gran pregunta es cómo articular economía de mercado y democracia, de forma que la primera sea un sostén de la segunda y no su espada de Damocles. La respuesta a esa pregunta no es para nada fácil, porque la economía de mercado, dejada a su propia dinámica, no augura más que deterioro en la naturaleza y en la vida de todos aquellos que no tienen nada que ofrecerle, mientras que la democracia, si no cuenta con los soportes institucionales adecuados, no puede ser viable en el largo plazo.

"Si un país ha de gobernarse democráticamente - se pregunta Robert Dahl一, ¿qué sería necesario? Cómo mínimo, debería poseer ciertos arreglos, prácticas e instituciones políticas, que significaran un importante avance, aunque no completo, hacia la consecusión de los criterios democráticos ideales" ${ }^{5}$. Sin esos arreglos, prácticas e instituciones políticas, la democracia corre el riesgo de no poder consolidarse ni poder durar ahí donde ha comenzado a establecerse.

Pero la institucionalidad democrática debe ser coherente, por el bien de la democracia, con un modelo económico que garantice a los ciudadanos una vida digna. Por avatares históricos de diverso signo ${ }^{6}$, el capitalismo de mercado ha terminado por articularse con la democracia, aunque, como dice Dahl, "son como dos personas unidas en un

\section{1}

Exclusión versus inclusión: democratización y reforma económica en Centroamérica 
tempestuoso matrimonio dividido por el conflicto, pero que aun así perdura porque ninguna de las dos desea separarse de la otra. Para cambiar el símil al mundo de la botánica, los dos existen en una especie de simbiosis antagónica"”.

Su principal antagonismo nace de la lógica excluyente que caracteriza a la economía capitalista de mercado y de la lógica incluyente que caracteriza a la democracia. ¿Cómo se resuelve el dilema entre ambas lógicas? Autores como Dahl creen que eso se logra haciendo que la lógica incluyente de la democracia predomine sobre la lógica excluyente de la economía capitalista de mercado. ¿Cómo se logra ese predominio? Hasta ahora, sostiene Dahl, ese resultado ha sido alcanzado, en las democracias más estables, mediante la intervención y regulación estatal en la economía, que ha permitido disminuir los efectos más perjudiciales de esta última ${ }^{8}$.

Sin embargo, esa intervención y regulación no suponen el fin de los antagonismos entre democracia y economía capitalista de mercado, sino sólo el control temporal de sus aristas más agudas. La conciliación entre las lógicas de una y otra -lógica incluyente versus lógica excluyente-sigue siendo un desafío de primera magnitud para las sociedades contemporáneas. Como dice Dahl, "la relación entre el sistema político democrático de un país y su sistema económico no democrático ha supuesto un formidable y persistente desafío para los fines y prácticas democráticos a lo largo del siglo XX. Este desafío seguramente proseguirá en el siglo XXI"'.

La embestida neoliberal de los años noventa - con sus programas de reducción del Estado y sus metas de expansión irrestricta del mercado- ha reavivado el desafío planteado por Dahl. En aquellas sociedades - como la salvadoreña - en las que la reforma neoliberal ha sido aplicada (o está siendo aplicada) sin contemplaciones, la lógica excluyente de la economia se ha convertido (se está convirtiendo) en la predominante, poniendo en jaque a la lógica incluyente de la democracia. En estas sociedades, la democracia está siendo socavada por la economía, siendo remota la posibilidad - por lo menos en el contexto de la actual coyuntura económica internacional y de la gran efusividad con la que han sido recibidos por las élites locales los programas neoliberales - de que la segunda pueda ser regulada por la primera, como sería de desear si lo que se pretende es construir sociedades estables, incluyentes y democráticas. 
Este ensayo es una reflexión sobre las vicisitudes de la democratización en Centroamérica, pero sin obviar los cambios económicos que la acompañaron y que ahora se han convertido en su peor amenaza. El argumento de fondo en estas páginas es precisamente este: que la democratización en Centroamérica - lo que se logró en los años ochenta y primera mitad de los noventa- está siendo socavada por los dinamismos de una economía terciarizada y las políticas económicas que le sirven de sostén. Es decir, que en Centroamérica el antagonismo entre democracia y economía capitalista de mercado se está inclinando en la actualidad a favor de la segunda, con todas las consecuencias sociales negativas que se derivan de una lógica económica excluyente no regulada ni controlada por instancia socio-política alguna.

A continuación se hará una aproximación al proceso de democratización en Centroamérica, para lo cual se fijará la atención en los dinamismos socio-políticos que se suscitaron en el periodo que va desde principios de los años ochenta hasta los primeros años noventa. Posteriormente, la atención será centrada en los procesos de reforma económica y la reforma-modernización del Estado; y finalmente, se hará un balance crítico del desempeño económico e institucional de Centroamérica en el año 2001. Mediante este balance se hará un intento por advertir la amenaza que supone, para el avance de la democratización en la región - y para el bienestar de la mayor parte de ciudadanos centroamericanos-, la vigencia de un modelo económico que apuesta por la terciarización, el libre comercio y un Estado mínimo.

\section{La democratización en Centroamérica: de la guerra a la paz}

Cuando hablamos de democratización, asumimos los aportes teóricos de la sociología y la ciencia política latinoamericana de la última década. En la reflexión sociológica y política latinoamericana y europea -tal como la han planteado autores como Guillermo O'Donnel, Manuel Antonio Garretón, Juan Linz, Robert Dahl, Huntington y otros- la democratización constituye un proceso de transformación política, mediante el cual se crean ordenamientos democráticos en sociedades donde estos no habían echado raíces o donde habían sido abolidos por la fuerza. La democratización consiste, entonces, en el proceso de transición de un régimen no democrático a otro que sí lo

\section{3}

Exclusión versus inclusión: democrattzoción y reformaeconómico en Centroamérica 
es, ya sea por la vía de recuperar instituciones y prácticas democráticas que habían existido previamente o por la creación de algo nuevo.

Tales ordenamientos democráticos no pueden ser construidos de una vez e inmediatamente; se trata de un proceso de largo aliento, en cuyo avance se debe pasar por determinadas etapas, siendo la más importantes, en la perspectiva de Leonardo Morlino, la transición estrictamente tal —que se inicia con la "crisis-caída o la crisis-transformación de un régimen democrático anterior" o de "un régimen tradicional o autoritario de otro tipo"-; la instauración de un nuevo régimen, que se logra "cuando una coalición de actores políticos, surgida de la transición, consigue crear y hacer vigentes las normas y las estructuras que caracterizan al nuevo régimen $y$, al mismo tiempo, los ocupantes de las nuevas estructuras de autoridad detienen el monopolio, o al menos, el control de la fuerza coercitiva"; y la consolidación, dos de cuyos rasgos más sobresalientes son, por un lado, "la formación de sólidos lazos entre actores políticos y actores sociales", por otro, el fortalecimiento "de la unidad de la coalición que está en la base del nuevo régimen" y, finalmente, "la fuerza de las instituciones políticas precisamente respecto de los actores sociales que las apoyan"10.

Para el caso de la democratización latinoamericana $-y$ de otras experiencias como la española, la portuguesa o la griega ${ }^{11}$ - los especialistas establecieron como un primer paso en la democratización la transición democrática que, consiste en lo fundamental, según Guillermo $\mathrm{O}$ 'Donnell, en un "intervalo que se extiende entre un régimen político y otro", siendo delimitada por un lado por el inicio del proceso de disolución del viejo régimen -esto es, el régimen autoritario-, a través de la implantación de un ejercicio democrático básico: elecciones competitivas, el pluralismo partidario y separación de poderes, etc. (liberalización), como por el establecimiento, en este caso, de alguna forma de democracia. Una vez agotada la transición —obtenidas las garantías democráticas básicas y establecido su sostén institucional mínimo- se estaría en condiciones de pasar a la siguiente etapa: la consolidación democrática, es decir, el ejercicio pleno de los derechos civiles y políticos de los ciudadanos, sostenido por un sólido tejido institucional y una cultura política anclada en valores democráticos.

Ciertamente, no se trata de un proceso lineal e inexorable, en tanto que las amenazas de "reversión autoritaria" siempre están presentes, 
incluso en la etapa de la consolidación. Como señala Rita Giacalone, siguiendo a Adam Przeworski, "aunque en la transición hacia la democracia se creen instituciones nuevas o se reactualicen otras existentes, dotadas de nuevo contenido, se trata, sin embargo, de una transacción contingente y no de un compromiso sustantivo (...). No existen garantías de que el proceso no pueda revertirse más adelante, aunque resulta obvio que cuando la nueva configuración institucional alcanza el nivel más alto —el de la Constitución- la garantía para impedir que ciertos intereses entren a la palestra política, o para que los que controlaban este escenario previamente queden relegados, es mayor"12. En la misma línea, Giacalone trae a cuenta dos de las más significativas conclusiones a las que llegó en su momento Przeworski: “1) la caída de un régimen autoritario no garantiza que el que le siga sea más democrático y 2) la transición hacia la democracia puede hacerse a costa de mantener intactas las relaciones económicas existentes"13.

La discusión anterior se inspiró en los procesos de democratización en los cuales no había una situación de enfrentamiento militar abierto, es decir, donde los regímenes autoritarios gozaban de un clima de relativa estabilidad. A Centroamérica llegó el desafío de la democratización en el marco de una aguda conflictividad militar. El desafío de la transición democrática se hizo presente con su exigencia de implantar los mecanismos básicos de la democracia para superar el legado autoritario, pero para que esos mecanismos fueran en verdad expresión de una democratización real había que terminar por la vía negociada con la conflictividad militar, la cual tenía una dimensión regional y otra local. Es decir, la pacificación se convirtió en una condición imprescindible para la democratización.

En la Centroamérica de los años ochenta ${ }^{1+}$, los focos nacionales de conflicto se volvieron inseparables de las tensiones regionales; ello

significaba que el proceso de paz debía abarcarlos a ambos. Si la regionalización supuso la transformación de los diversos problemas nacionales en un problema regional, es decir, la unificación de los conflictos locales en un solo conflicto centroamericano, la superación de la crisis regional exigía "la integración de las soluciones propuestas a las crisis de cada país en la búsqueda de una solución unificada para toda el área de Centroamérica"15. Lo nacional se imbricaba con lo regional; avanzar en la solución de los conflictos locales suponía avan- 
zar en la distensión regional. Y, para que ambas dinámicas tuvieran éxito, era importante no sólo el papel que pudieran jugar los actores nacionales, sino también los actores internacionales, entre los cuales el gobierno de Estados Unidos ocupaba un lugar de primer orden.

Asimismo, si Estados Unidos no moderaba su percepción y su actuación en Centroamérica, y si esa moderación no se conjugaba con un mayor protagonismo de la comunidad internacional y de los actores nacionales-regionales a favor de la paz, el proceso de pacificación en no tendría visos de obtener resultados positivos. No es desatinado sostener que el proceso de pacificación regional avanzó decisivamente y se encaminó a su recta final una vez que los factores señalados se conjugaron en torno al propósito de lograr una solución no militar a los conflictos nacionales y a las tensiones regionales.

Al cierre de la década de los años 80 , no era improbable que se abriera paso una solución pacífica para resolver los conflictos de El Salvador y Guatemala. Era claro que un desenlace negociado no iba a ser fácil y que para avanzar hacia el mismo había que superar importantes obstáculos. Pero los avances en materia de distención regional permitían abrigar esperanzas fundadas de que en la década siguiente - la década de los años 90 - se podrían obtener resultados positivos en la solución de los conflictos nacionales más agudos.

Para el logro de esos resultados fueron cruciales los esfuerzos del Grupo de Contadora (1983) y las reuniones de Esquipulas I y II. De Contadora, Manuel Montobio dice lo siguiente: "Contadora nace de la crisis centroamericana, se dirige hacia ella, pero sin embargo va más allá. La construcción de una vía alternativa de solución del conflicto a corto plazo se convierte a medio plazo en leit motiv para su constitución en precedente en sentido contrario al tenido respecto a Estados Unidos: frente a un orden latinoamericano determinado en lo fundamental por la relación de cada uno de los actores con Estados Unidos, Contadora constituye el primer intento de articulación de respuestas latinoamericanas frente a problemas latinoamericanos, de búsqueda ... de vías de solución alternativa a un conflicto erigido en preocupación prioritaria de la agenda latinoamericana, punto de inflexión hacia la construcción de un nuevo orden latinoamericano con mayor participación de los actores regionales y mayor margen de autonomía relativa frente a la potencia hegemónica"16. 
Contadora trasladó la responsabilidad del proceso de pacificación a los países centroamericanos, los cuales, sin embargo, no estaban listos para asumir por su propia cuenta los retos que aquél planteaba. Tras el fracaso relativo de Contadora, "toda la región centroamericana había quedado sumida en una situación de desesperanza, en la cual apenas se apreciaba otra salida que la de la violencia y las armas"17. En este marco, los gobiernos de Guatemala y Costa Rica hacen gala de una capacidad de iniciativa pocas veces vista en la región. Gracias a sus esfuerzos, se realizan dos importantes reuniones - Esquipulas I y Esquipulas $\mathrm{II}^{18}$ - que serán cruciales para avanzar en la pacificación de Centroamérica. De la primera reunión, dos fueron los logros más significativos: a) los cinco presidentes centroamericanos hacen una opción por la democracia y por la cooperación como vía para resolver los conflictos; y b) se acepta la representatividad del gobierno de Nicaragua, así como la necesidad de su participación activa para resolver los problemas del área ${ }^{19}$.

De la segunda reunión, celebrada en agosto de 1987, salió el "Procedimiento para establecer la paz firme y duradera en Centroamérica". Este documento, sabiamente, logró articular en una propuesta coherente tanto la dimensión regional del conflicto como su dimensión local (nacional). Asimismo, se trató de una propuesta que no se reduce a los problemas militares y de seguridad, sino que inserta la solución de estos problemas en un horizonte más amplio, como lo es el de la democracia, la justicia y el desarrollo ${ }^{20}$.

Manuel Montobbio destaca cuatro aspectos relevantes en el "Procedimiento". En primer lugar, la idea de "simultaneidad", en un doble sentido: "aplicación simultánea de los compromisos por todas las partes y aplicación simultánea de éstos como un todo indivisible por cada parte". En segundo lugar, "simetría", lo cual "implica la asunción de obligaciones igualmente por todas las partes, evitando la atribución formal de una responsabilidad diferenciada a una de ellas". En tercer lugar, "cronograma", que implica la atribución de plazos concretos, precisamente definidos, para la ejecución de los compromisos contraídos, calendarizándola". Y, en cuarto lugar, "verificación", a partir de la cual se estableció "tanto el carácter verificable de los compromisos como mecanismos independientes a tal efecto" $"$.

En suma, con Esquipulas II, no sólo se abrió un espacio más propicio para el apoyo de la comunidad internacional - concretamen-

\section{7}


te, a través de la Organización de las Naciones Unidas (ONU)-, sino que se desencadenaron una serie de procesos políticos nacionales, derivados directamente de las exigencias de su ejecución o como resultado no esperado inicialmente, pero que la lógica del cumplimiento del "Procedimiento" hizo necesario asumir. Sin embargo, tras un periodo fructífero -en sus primeros 90 días- Esquipulas II perdió impulso y entró en una fase de estancamiento a lo largo de $1988^{22}$.

Si bien en la Cumbre de San José (enero de 1988) se plantearon temas sensibles relativos a la verificación, es en la Cumbre de Costa del Sol (febrero de 1989) cuando se da un nuevo impulso al proceso global, en tanto que en ella Nicaragua asumió una serie de compromisos de democratización y reconciliación nacional, al tiempo que se comprometió a realizar unas elecciones anticipadas, en febrero de 1990. Siempre en 1989, se realizó la Cumbre de Tela, la cual arrojó los siguientes resultados: a) desmovilización de la "contra"; b) no utilización del territorio nacional para agredir a otros Estados; y c) establecimiento de la Comisión Internacional de Apoyo y Verificación (CIAV) y la Misión de las Naciones Unidas para Centroamérica (ONUCA). Las dos cumbres siguientes, celebradas en 1990 -la de Montelimar y la de Antigua - dan como resultado la aprobación del Plan de Acción para Centroamérica, con lo cual - como señala Montobbio- "el centro de gravedad del proceso pasa progresivamente de lo político (especialmente centrado en Nicaragua), a la seguridad, y de ésta a lo socioeconómico" 23 .

A principios de la década de 1990 , el proceso de pacificación regional comenzaba a dar sus mejores frutos, entre los cuales dos de los más importantes fueron los avances hacia la desmilitarización de Honduras y la celebración de elecciones en Nicaragua, las cuales permitieron el relevo político del FSLN al frente del gobierno de ese país. Con ello, se despejaba el camino para la desactivación de los dos principales focos de tensiones regionales. El aporte de Esquipulas II fue crucial para avanzar hacia ese desenlace ${ }^{25}$.

Pero no sólo eso. Y es que con Esquipulas II se creó el marco propicio para que los procesos de pacificación nacionales pudieran desarrollarse según los ritmos, necesidades y condiciones de cada país. Ciertamente, la incidencia de Esquipulas II fue mayor en el proceso nicaragüense, dada la naturaleza del régimen sandinista y el modo cómo 
era visto por sus vecinos y Estados Unidos. Pero Esquipulas II también ofreció un marco de consideraciones sustantivas y adjetivas para la resolución negociada de conflictos nacionales. "Entre las primeras, la aceptación y determinación de la legitimidad de los gobiernos, el tratamiento de simetría operativa de los movimientos rebeldes y el principio de negociación política para poner fin al conflicto interno. Entre las segundas, la concesión de amnistía, la concertación del cese de fuego dentro del marco constitucional, el desarme de las fuerzas irregulares que estén dispuestas a acogerse a la amnistía, y el diálogo entre el gobierno y los grupos no armados de la oposición política"26.

En el plano de los conflictos nacionales, tanto El Salvador como Guatemala gozaron de un clima regional propicio para avanzar, con sus propios ritmos, en sus respectivos procesos de pacificación ${ }^{27}$. La culminación de ambos procesos fue la firma de unos Acuerdos de Paz -en El Salvador en $1992^{28}$ y en Guatemala en $1996^{29}$ - mediante los cuales se hizo posible el fin de los conflictos militares, la inserción de los grupos armados a la vida civil - luego de su conversión en instancias políticas legales-, la reducción-depuración del ejército, una reforma de los sistemas de justicia y la elaboración de sendos informes - a cargo de unas comisiones de la verdad- en los que no sólo se exponían las evidencias de los crímenes de guerra más atroces y significativos de la década de los años 80 , sino también la identidad de sus responsables.

En definitiva, la primera fase de la democratización - la transición- fue, en Centroamérica, simultánea con la pacificación; más aún, dependió fuertemente de ella, al punto que sólo se pudo avanzar en ella cuando la paz fue conquistada. Dicho de otra manera, en Centroamérica, la pacificación fue la condición esencial para la transición -que sólo se pudo completar cuando finalizaron los conflictos armados que se suscitaron desde finales de los años setenta y a lo largo de la década de los ochenta-. Superados los conflictos militares, la consolidación democrática aparece como algo incierto; más aún, no hay consenso entre los especialistas acerca de la finalización de la transición, sobre todo cuando el fantasma de la reversión autoritaria no ha sido exorcizado del todo y cuando el esquema económico predominante ha aumentado la brecha entre ricos y pobres, condenando a la mayoría de centroamericanos a la marginalidad y la exclusión. 


\section{Reforma económica y modernización del Estado en Centroamérica}

Ante todo, se tiene que decir que los Estados centroamericanos han venido sufriendo profundos cambios a lo largo de la década de los años ochenta y noventa. En la misma línea, también el sector de la gran empresa privada ha atravesado por importantes transformaciones en su posicionamiento económico y político. Estas dinámicas estatales y empresariales no han sido ajenas a los desafíos planteados por la globalización y los tratados comerciales - aunque también han intervenido factores "endógenos" que no pueden dejarse de lado, como los conflictos internos y sus secuelas, el estancamiento económico y los elevados niveles del gasto público que sacudieron a Centroamérica a lo largo de los años ochenta.

Lo que aquí se entenderá por "reforma económica" atañe a las medidas económicas que se han ejecutado desde el Estado para adecuar los aparatos productivos al cambiante entorno mundial y para hacer frente el estancamiento y al declive de los ejes productivos tradicionales, esto es, la agricultura y la industria. Dicho de otro modo, la reforma económica, tal se entiende aquí, hace referencia a la respuesta de los Estados centroamericanos a los desafíos de la globalización y a los retos planteados por la crisis del modelo agroexportador y agroindustrial ${ }^{30}$.

Por supuesto, es importante prestar atención a los factores "endógenos" que motivaron las presiones empresariales, las inercias burocráticas y los compromisos políticos obstaculizaron la reforma que conduciría a la modernización estatal. De estos tres aspectos, el más relevante fue el ascenso de la derecha económica a las altas esferas estatales. Este "asalto" empresarial del Estado fue decisivo para que su reforma y modernización se agotara en su reducción, privatización de sus activos y pérdida de protagonismo económico, al tiempo que desde su mismo seno- los sectores empresariales enquistados en su interior se beneficiaban de las decisiones económicas emanadas del Estado. Se trata de un círculo vicioso, en virtud del cual quienes gestionan el aparato del Estado no sólo representan directamente a poderosos intereses empresariales, sino que usan el poder del que gozan para debilitar al Estado y fortalecer a los grupos de poder económico de los que son portavoces. 


\subsection{El "asalto" empresarial del Estado: el fortalecimiento del sector financiero}

A partir de los años ochenta, en Centroamérica se comenzó a operar una rearticulación en las relaciones entre los grandes empresarios y el Estado. En virtud de esta rearticulación, los empresarios irrumpieron en el ámbito político y comenzaron a ocupar posiciones estratégicas en el Estado. Los empresarios no sólo se vincularon a fuertes partidos políticos de derecha, sino que desplazaron a los militares, como principales actores de la conducción estatal.

Si en la década de los años treinta, en Guatemala, Honduras, Nicaragua y El Salvador, los empresarios "decidieron" retirarse de la política, en la década de los años ochenta tomaron la decisión de insertarse de nuevo en ella. La presencia empresarial en los Estados centroamericanos ha permitido que los intereses de los grupos de poder económico se hagan sentir directamente en las esferas estatales, desde donde se han diseñado e implementado las políticas económicas que responden mejor a aquellos intereses. En algunos países, la imbricación entre los intereses empresariales y las dinámicas estatales ha sido más estrecha que en otros, pero en conjunto la orientación proempresarial de los Estados centroamericanos ha terminado por convertirse en su característica más notable.

Asimismo, no todos los grupos empresariales tienen — desde finales de los años ochenta en adelante- la misma influencia en la dinámica estatal. Los sectores vinculados al capital financiero son los que mejor se han posicionado, no sólo en el ámbito económico, sino también en el ámbito político. Este predominio del sector financiero contrasta con el declive de la influencia y del poder de agricultores y empresarios de la industria.

La fortaleza del sector financiero centroamericano se sostiene en alianzas estratégicas con grupos financieros internacionales que, por su parte, se llevan una importante porción de las ganancias dejadas por los activos estatales privatizados. La otra porción de esos activos está terminando en manos de los empresarios controlan los principales bancos e instituciones financieras de la región. La modernización del Estado -necesaria, dada la obsolescencia de las estructuras estatales tradicionales - se tradujo, en la práctica, en una reducción drástica de sus responsabilidades económicas. Las reformas que se impulsaron 
-y se impulsan - para lograr la proclamada modernización estatal ban tenido dos ejes básicos: por un lado, recortes de personal en la burocracia del Estado y por otro, el traslado de empresas (o instituciones) públicas al sector privado.

En suma, las reformas del Estado en Centroamérica están dejando como gran ganador al sector financiero, en tanto que las empresas públicas privatizadas han sido adquiridas —están siendo adquiridaspor los grupos financieros más poderosos. Es decir, la reforma del Estado ha sido entendida como privatización de las empresas públicas presuntamente menos rentables. La reducción (o achicamiento) del Estado ha sido entendida como desmantelamiento de sus estructuras, despidos masivos y renuncia a diseñar e implementar políticas públicas. Lentamente, en Centroamérica el Estado se ha ido convirtiendo - pese a las crecientes demandas sociales - en un mecanismo más de la lógica empresarial —aunque con mayores resistencias ahí donde la lógica de la sociedad no fue socavada en el pasado reciente por la represión política o la guerra. - Piénsese en Costa Rica, como un caso relativamente distinto a lo que sucede en el resto de países centroamericanos. Así pues, la fisonomía de las sociedades centroamericanas actuales está claramente definida por la privatización de entidades dirigidas anteriormente por los Estados. Quienes defienden la privatización, afirman que se trata de una necesidad para modernizar los aparatos estatales, optimizar su funcionamiento e imprimirles a las economías competitividad y dinamismo. Este último objetivo es de gran importancia, sobre todo en un contexto mundial sobredeterminado por la globalización de las economías, pero no está claro cómo la privatización irrestricta pueda conducir automáticamente a ello.

\subsection{Globalización, reforma económica y reforma-modernización del Estado}

Las privatizaciones se dan en un contexto de agotamiento del modelo agroexportador y monocultivista, que dominó en las economías centroamericanas durante buena parte del siglo XX. Se ha suscitado una transformación sustancial en las economías del istmo, en virtud de la cual el agro ha pasado de ser el eje fundamental a convertirse, virtualmente, en una carga para los sistemas económicos. El ejemplo más claro se tiene con la caída de los precios internacionales del café. Todo esto ha provocado que muchos gobiernos pongan sus ojos en

\section{2}


las ciudades, profundizando la desocupación en el campo, la migración a las ciudades y el descontento de los antiguos productores de café, algodón y otros cultivos que otrora fueron el pivote de la agroexportación. Nos encontramos en economías centradas en renglones como la maquila y los servicios. Ello explica el florecimiento momentáneo de la venta de servicios de telefonía, una de las áreas sometidas a privatización.

Los Estados centroamericanos han perdido en las tres últimas décadas la autonomía relativa de la alguna vez gozaron. Copados por los empresarios, sin suficientes recursos y con una serie de vicios del pasado - corrupción, compadrazgos y abusos de poder-, la capacidad estatal para distanciarse de los grupos más influyentes y tomar decisiones está llegando a su punto más bajo. Son estos estados debilitados los que tienen que hacer frente a los desafíos que plantea la globalización, así como a los desafíos que platean los tratados comerciales regionales. Tanto la globalización como los tratados comerciales regionales no obedecen a la lógica de los Estados. Más bien, éstos deben someterse a la lógica de aquellos. La lógica de la globalización, por un lado, es la lógica de los grandes conglomerados de poder económico a nivel mundial. Son esos grandes conglomerados los que determinan el lugar y las posibilidades de cada nación en ese gran mercado que es el mundo globalizado.

La lógica de los tratados comerciales regionales es la lógica de los grandes empresarios locales que pretenden - a partir de esos tratados- garantizarse un espacio favorable en el mercado mundial. Los Estados centroamericanos, de la mano de los grupos empresariales más importantes, se han embarcado en la firma de acuerdos comerciales, cuyo marco global ha sido impuesto por Estados Unidos. La apuesta de los empresarios centroamericanos (y de sus respectivos estados) es que, "respaldados" por esa potencia económica que es Estados Unidos, la inserción en el mundo globalizado va a ser más provechosa para ellos. En esos tratados, sin embargo, la capacidad de maniobra de los estados centroamericanos es sumamente reducida. La razón es simple: se trata de acuerdos firmados entre desiguales: por un lado, Estados Unidos, Canadá y México, con su gran iniciativa de apertura comercial, y, por otro, el resto de países centroamericanos que se tendrán que insertar en un esquema de libre comercio previamente definido. 
En este sentido, la reforma (y modernización) del Estado es uno de los problemas más importantes en las circunstancias actuales centroamericanas. Tal problema es objeto de encendidos debates y de posiciones excluyentes. Obviamente, reforma del Estado no significa, ni por cerca, privatización a ultranza y sin restricciones de los activos estatales, como se ha querido hacer ver por los adalides de la expansión sin límites del mercado. Este enfoque tiene a la base la idea errónea de que la corrupción y la administración deficiente de la cosa pública por parte del Estado es la única causa de los problemas socioeconómicos.

El remedio que proponen los defensores de la liberalización irrestricta no es tan acertado. Supone reducir al Estado a la expresión mínima y ello implica, a su vez, dejar a la población sin políticas que garanticen el acceso a los bienes básicos a la salud pública, educación y pensiones. Tampoco las privatizaciones conducen necesariamente a la eliminación de los monopolios, ni son garantía de la libre competencia. Lo que se ha dado es el surgimiento de nuevos monopolios - eso sí, en manos privadas-, favorecidos por la falta de regulaciones y alentados por los empresarios que tienen cargos de gobierno.

El Estado resulta necesario para garantizar un mínimo de condiciones de vida decentes para la población, aunque es innegable que hay que reformarlo. En Centroamérica, la regla general es que los Estados se han visto en manos de gobernantes corruptos, que los ha manejado - los manejan- como empresas particulares, y eso no debe ser tolerado por la sociedad. La reforma del Estado debe apuntar, entre otras cosas, hacia la erradicación de las prácticas corruptas y hacia el diseño de políticas públicas que ataquen los problemas socioeconómicos que golpean a la población. Obviamente, un Estado "capturado" 31 por las élites empresariales -como el que se ha venido gestando durante las dos últimas décadas en Centroamérica- tiene un margen de maniobra que hoy por hoy es poco favorable para potenciar el desarrollo social en la región.

\subsection{Reforma económica, reforma-modernización del Estado y exclusión social}

La reforma económica ha avanzado incontenible en Centroamérica durante las décadas de los años ochenta y noventa. A partir de la implementación de los programas de ajuste y estabilización de los 
años ochenta hasta los programas de privatización de los años noventa, los aparatos productivos en el área han sufrido cambios notables. Desde el punto de vista de la expansión del marcado y del florecimiento de las actividades comerciales y financieras, la reforma económica ha sido un éxito. Todavía quedan activos públicos por privatizar - los sistemas de salud pública y la red de puertos, entre otros-, pero importantes rubros han sido trasladados a manos privadas: pensiones de retiro, energía eléctrica y telecomunicaciones. La reforma y modernización del Estado se han quedado cortas en cuanto a los ideales que se abanderaron para llevarlas adelante. La reforma y modernización pretendían no sólo erradicar vicios propios de los Estados centroamericanos, como la corrupción y el clientelismo, sino crear unos aparatos estatales eficientes y activos en la promoción y defensa de los derechos de los ciudadanos. La idea era construir un Estado democrático de derecho en cada uno de los países de la región. Nadie podía negar que la reforma y modernización de los Estados centroamericanos era necesaria. Sin embargo, un balance del saldo obtenido en la materia no deja lugar a dudas acerca de lo poco que se ha obtenido en la edificación de ese Estado democrático de derecho.

Los Estados centroamericanos han cambiado en las últimas dos décadas. En cierto modo, han sido reformados, pero no se han modernizado. Prácticas tradicionales, como la corrupción y el clientelismo, persisten como en los viejos tiempos. Eso sí, los Estados centroamericanos han perdido protagonismo económico y se han hecho más pequeños, mediante los recortes de personal y el traslado de sus activos a manos privadas. En otras palabras, los Estados se han achicado y han perdido fuerza. La reforma y modernización de los Estados en Centroamérica no han ido más allá de eso. Como resultado de ello, los Estados centroamericanos no sólo son menos autónomos, sino que se han vuelto cada vez más incapaces de responder a las crecientes demandas sociales, agudizadas por el impacto negativo de la reforma económica.

En efecto, el costo social de la reforma económica - terciarización, ajuste, estabilización y privatización - ha sido asumido por la mayor parte de ciudadanos, mientras que los beneficios han ido a parar a manos de los sectores minoritarios vinculados al comercio y las finanzas. La pobreza, pues, lejos de disminuir, ha aumentado; la brecha entre ricos y pobres se ha ampliado, con el agravante de la pérdida de fuerza y protagonismo del Estado -única instancia capaz impulsar

Exclusión versus inclusión: democratización y reformo económica en Centroamérica 
medidas de equidad social-. Tal como se reconoce en el informe Estado de la región (1999), "a finales del siglo XX la equidad social es un reto pendiente en Centroamérica. El fin de los conflictos militares, la democratización de los regímenes políticos y la modernización de sus economías no han logrado paliar las históricas inequidades sociales en la región. Estas inequidades, o brechas de equidad, son múltiples: entre zonas urbanas y rurales, entre ricos y pobres, entre indígenas y no indígenas, entre hombres y mujeres. La región es, todavía, el escenario de una desigualdad social que lesiona el desarrollo humano de las mayorías. Millones de centroamericanos no tienen, o tienen un acceso muy precario, a oportunidades para tener un empleo de buena calidad o para atender sus necesidades de salud" ${ }^{32}$.

\section{Centroamérica en el 2001: el legado de dos décadas de democrati- zación, reforma económica y reforma-modernización del Estado ${ }^{33}$}

Si queremos tener una idea del legado que han dejado a Centroamérica dos décadas de democratización, reforma económica y reformamodernización del Estado es útil e iluminador hacer un recuento de los dinamismos políticos, económicos y sociales más recientes. Con este balance concluirá este ensayo; en el mismo queda en evidencia la endeblez de unos ordenamientos democráticos que, con unos aparatos estatales diezmados en sus recursos y autonomía, no logran responder a los graves problemas sociales - como la pobreza creciente, la marginalidad y el deterioro de las condiciones de vida de la mayor parte de la población- agudizados por el impacto de la reforma económica, en sus variantes de ajuste, estabilización y privatización.

El año 2001 resume bien las contradicciones entre el modelo económico incubado en Centroamérica desde los años ochenta y las exigencias de la democratización. La batalla está siendo ganada por la expansión del mercado y sus efectos sociales negativos; la democracia, con sus valores de igualdad, de participación socio-política y de potenciación de la ciudadanía, está siendo abatida por la lógica de la economía. Los Estados centroamericanos, sin modernizarse del todo y copados por los grupos empresariales más poderosos, han contribuido al estancamiento de la democratización.

a) Elecciones y consolidación democrática. El inicio del nuevo siglo estuvo marcado, en Centroamérica, por un intenso ambiente electoral 
que involucró, directa o indirectamente, a todos los países del área. En este ambiente, fue puesto en la palestra de discusión el papel de la institucionalidad democrática centroamericana, tomando como marco global, en primer lugar, el camino recorrido desde el período de transición gestada en los años ochenta y, en segundo lugar, los retos que plantea el nuevo escenario mundial en un siglo que comienza. En el caso hondureño, nicaragüense y costarricense, el referente ineludible sería el desempeño electoral que desembocó en la elección de tres nuevos mandatarios rodeados por un ambiente de renovación y de esperanzas de cambio. En términos generales, el desenlace electoral dejó muchas lecciones para los centroamericanos.

En primer lugar, la aún precaria institucionalidad electoral vigente en el área, en tanto que prevalecieron las campañas sucias entre rivales, los señalamientos de partidarización en los tribunales electorales, el movimiento de fuertes intereses que impiden la emergencia de fuerzas políticas alternativas y una serie de factores que impidieron el satisfactorio desempeño de los eventos electorales. En segundo lugar, la experiencia acumulada obliga a la renovación y modernización de los partidos políticos, de cara a su creciente desvinculación con la ciudadanía y a la ausencia de proyectos apegados a la realidad. Dicho en otros términos, la clase política en general ha adolecido de tal miopía que se ha dado pie al descontento e incredulidad ciudadanas hacia las promesas incumplidas.

En suma, en Centroamérica se pretende lograr la consolidación de sus sistemas democráticos con pocas armas y con modestos logros reales. Sobran los proyectos y las iniciativas a todo nivel, pero además saltan a la vista del observador los grandes vicios enquistados durante los más oscuros hitos de la historia política regional. Siguen presentes la corrupción, la discrecionalidad, el amiguismo, las prebendas, el compadrazgo político, el autoritarismo, la apatía, el interés propio y la exclusión.

b) Dependencia y vulnerabilidad de las economias. En general, la economía centroamericana tuvo un mal desempeño en el 2001. La paulatina disminución del crecimiento del PIB en 2000 y el deterioro de la balanza comercial era ya un signo de alarma para las economías nacionales a finales del año pasado. Pero lo que más causa preocupación es la creciente dependencia de los factores externos y la vulnerabilidad de las economías centroamericanas. Tal dependencia se hizo

\section{7}

Exclusión versus inclusión: democratización y reforma económica en Centroamérica 
más palpable tras el decadente desempeño de la economía estadounidense que arrastró inexorablemente a las débiles economías mexicana y centroamericana. Los atentados del 11 de septiembre del 2001 en Estados Unidos agravaron aún más la situación, a la par de la sensación de incertidumbre reinante en los círculos comerciales y financieros. Todo ello, junto a las variables internas de cada nación, propició la debacle de los indicadores económicos.

c) Maquilas y tratados comerciales. Un tema preocupante es el de la actividad maquilera en la región, para la cual los gobiernos han dirigido toda clase de incentivos fiscales y programas de financiamiento. Esta apuesta por el sector maquilero ha sido alimentada por los incentivos comerciales concedidos por Estados Unidos en el 2001 (la ampliación de la ICC) y por la negociación de tratados de libre comercio. Así, lo que ha caracterizado a la diplomacia centroamericana en los últimos tiempos son los intensos cabildeos internacionales para "amarrar" tratados comerciales de manera multilateral o bilateral y ampliar los mercados locales.

En mente de los mandatarios centroamericanos y de sus respectivos gabinetes económicos ha estado el megaproyecto del ALCA, que pretende instaurar el libre comercio desde Alaska a la Tierra de Fuego y convertir al continente entero en el bloque comercial más grande del mundo. El cabildeo internacional se consolidó con la celebración de reuniones de los llamados Grupos Consultivos, a fin de mantener los programas de cooperación y de financiamiento destinados a la reconstrucción y modernización de Centroamérica.

d) La irresuelta demanda social. El repunte en la mejora de las condiciones de vida de los centroamericanos experimentado a principios de la década de los noventa ha tendido a estancarse en los últimos años. Los éxitos logrados en aquellos años son palpables: reducción del analfabetismo, mayor cobertura de los servicios básicos, mayor índice de escolaridad, y una tímida reducción de los niveles de pobreza.

Sin embargo, los avances no han estado a tono con las crecientes demandas sociales y al crecimiento poblacional. En los últimos dos años se agudizaron los problemas sociales en la mayoría de países y las brechas existentes entre los propios países y al interior de los mismos siguen ampliándose. Los avances en la reducción de la pobreza han sido modestos, por no decir nulos. Los niveles de exclusión, vulnera- 
bilidad y de precariedad en las regiones indígenas y atlánticas quedaron de manifiesto tras el impacto de los fenómenos naturales. De ahí que la gestión de riesgos y de los recursos naturales haya sido una deuda no suplida.

Por otro lado, los bajos niveles de gasto público y la ausencia de políticas públicas en el área se han traducido en un creciente descontento popular que ven, con ojos críticos, la labor de la clase política y que, en el peor de los casos, ha desencadenado acciones de violencia. La baja inversión en Salud y Educación se refleja en la precariedad de los sistemas nacionales que dan cobertura a dichas áreas; y la situación se complica en las zonas rurales.

Asimismo, el problema de la delincuencia se agudizó en todos los países sin excepción. Los secuestros estuvieron a la orden del día en Guatemala, Honduras y El Salvador. El tráfico de drogas y vehículos siguió siendo un gran desafío para los cuerpos policiales de la región, sin dejar de lado el desafío de la amenaza terrorista que emergió luego de los atentados del 11 de septiembre del 2001. Finalmente, los niveles de desempleo y subempleo empeoraron durante el año - principalmente en Panamá- como consecuencia del cierre de empresas y de plantaciones agrícolas — de café y banano fundamentalmente.

e) La apuesta por la integración. El años 2001 dejó como desafío de primera importancia la necesidad de revisar el proceso de integración centroamericana y la incipiente - por no decir ineficienteinstitucionalidad que la sustenta. Nunca antes se había cuestionado con tanta vehemencia el papel de las instituciones creadas para garantizar las relaciones políticas y económicas de las naciones que conforman el área. Basta dar un vistazo retrospectivo para darse cuenta de los largos e interminables diferendos entre todas las naciones, desde Belice, pasando por Nicaragua y hasta Panamá.

El papel de la Corte Centroamericana de Justicia y del Parlamento Centroamericano ha quedado en entredicho y sin embargo pareciera que no hay suficiente voluntad política para despertar esas instituciones del letargo en que han caído. En el momento actual, la integración regional se presenta como un imperativo, dada la reducida capacidad - importancia - de cada nación en particular dentro del escenario mundial. No sólo se trata de unificación aduanera y de corredores 
logísticos, sino que dicha integración implica un cambio de mentalidad que, obviamente, no se dará de la noche a la mañana.

En definitiva, Centroamérica inició el nuevo siglo atrapada en la contradicción que se vino gestando a lo largo de la década de los años noventa: la contradicción entre un modelo económico terciarizado y la situación de marginalidad social creciente de la mayoría de sus habitantes. Con vaivenes, los aparatos productivos se han ido adecuando a las exigencias de la globalización, al tiempo que han podido sortear, no sin dificultades, la crisis de los ejes tradicionales de producción. A tono con el cambio económico, los grupos de poder económico vinculados al sector terciario han visto crecer y multiplicar su riqueza.

Sin embargo, la mayoría de la población no ha mejorado sus niveles de vida, sino más bien todo lo contrario. Los niveles de pobreza y de marginalidad han persistido, como en las décadas previas al estallido de los conflictos militares de los años ochenta. La expansión del mercado, el crecimiento económico, las privatizaciones y los tratados comerciales están dejando como ganadores a una minoría de banqueros, financistas y comerciantes. El resto - la mayoría-continúa debatiéndose en la pobreza. Para esta mayoría, la reforma económica no ha dejado un saldo positivo. Entre tanto, la reforma política -la democratización - exige dosis mínimas de equidad social para poder sostenerse en el tiempo. Es esa equidad social precisamente la que no se ha alcanzado; es su ausencia la que está socavando los logros obtenidos en materia de democratización política, una vez que los conflictos militares se fueron resolviendo por la vía negociada.

La reforma económica, pues, no ha sido un complemento de la reforma política, sino uno de sus principales obstáculos. Los Estados centroamericanos hicieron su apuesta por la reforma económica, perdieron protagonismo y propiciaron - a partir de una agenda neoliberal - la terciarización de las economías y el fortalecimiento del sector financiero. Su desarticulación no llevó a su modernización, sino a su debilitamiento. Unos Estados debilitados y cooptados por los grupos de poder económico difícilmente pueden hacer algo para potenciar la democratización y propiciar la equidad social en Centroamérica. Así las cosas, la economía continuará divorciada de la política; el crecimiento económico no se traducirá en desarrollo económico y social; la brecha entre ricos y pobres se seguirá ampliando; y 
la inestabilidad social seguirá a la orden del día. De lo que se trata entonces es de integrar estas dos lógicas contradictorias, la economía y la política, así como superar el divorcio entre la reforma estatal y la organización y bienestar de los sectores mayoritarios de la población, puesto que, de lo contrario, las bases de la integración social continuarán siendo amenazadas por la inestabilidad y la violencia ${ }^{34}$.

San Salvador, 25 de noviembre de 2002

NOTAS

1. Cfr., González, L. A., "Acerca de la transición a la democracia”. En Cardenal, R., González, L. A. (Comp.), El Salvador: la transición y sus problemas. San Salvador, UCA/editores, 2002, pp. 117 y ss.

2. Cfr., Ferrer, A., Historia de la globalización. México, FCE, 1996.

3. Judson, $\mathrm{F}$., "El ajuste y las agendas nacionales centroamericanas". $E C A$, No. 597-598, julio-agosto de 1998, p. 612.

4. Cuando las elecciones y las libertades que le están asociadas se encuentran institucionalizadas es probable que las poliarquías resistan o se consoliden. O'Donnell, G., "Ilusiones sobre consolidación". Revista Nueva Sociedad, 144, pp 70-89. Se pude consultar también Cheresky, I., Pousadela, I. (Comp.), Politica e instituciones en las nuevas democracias latinoamericanas. Buenos Aires, Paidós, 2001.

5. Dahl, R., La democracia. Una guia para ciudadanos. Madrid, Taurus, 1999, p. 97.

6. Cfr., González, L. A., "Democracia liberal clásica y capitalismo". Realidad, No. 24, noviembre diciembre de 1991, pp. 765-816; González, L. A., "Globalización y neoliberalismo". ECA, No. 603, enero de 1999, pp. 53-68.

7. Dahl, R., La democracia..., p. 187.

8. Ibid., p. 199.

9. Ibid., p. 201.

10. Morlino, L., "Los autoritarismos". En AAVV, Manual de ciencia política. Madrid, Alianza, 1996, pp. 156-165

11. Cfr., Santamaría, J. (Comp.), Transición a la democracia en el Sur de Europa y América Latina. Madrid, Centro de Investigaciones Sociológicas, 1981.

12. Giacalone, R., "Transición política y constitución: una revisión de América Latina". En Mariñez Navarro, F., Ciencia política: nuevos contextos, nuevos desafíos. México, Noriega, 2001, p. 121

13. Ibid., p. 121.

14. En esta parte seguimos las ideas desarrolladas en González, L. A., "Centroamérica: proceso de paz y perspectivas de futuro". XXII Coloquio de Antropología e Historia Regionales, Michoacán, El Colegio de Michoacán, 2000, pp. 85 y ss.

15. Ellacuría, I., "Regionalizar la paz, no la guerra". En Ellacuría, I., Veinte años de bistoria en El Salvador (1969-1989). San Salvador, UCA/Editores, 1991, 1011. 
16. Montobbio, M., La metamorfosis de pulgarcito. Transición politica y proceso de paz en El Salvador. Barcelona, Icaria-Antrazyt-FLACSO, 1999, p. 142

17. Ellacuría, I., "Propuestas de solución en el marco de Esquipulas dos". En Ellacuría, I., Veinte años de historia en El Salvador (1969-1989). San Salvador, UCA Editores, 1991, p.1171, Tomo II

18. Hubo dos reuniones más bajo el mismo nombre: Esquipulas III y Esquipulas IV, en las cuales se afinaron detalles de las reuniones anteriores o exhortaba a cumplir los compromisos adquiridos por las partes. Ver, "¿Hacia dónde vamos? Socialismo y Acuerdos de Esquipulas". Envio, No, 91, enero-febrero de 1989, pp. 1-133; “Altibajos del diálogo. Inestabilidad centroamericana”. Envío, No. 84, junio-julio de 1988, pp. 1-18

19. Montobbio, M., La metamorfosis..., p. 148

20. Ver Ellacuría, I., "Propuestas de solución en el marco de Esquipulas dos". pp. 1172-1173; Montobbio, M., La metamorfosis..., pp. 150-151; "Centroamérica. Entre la guerra y la paz". Envio, No. 81, marzo de 1988, pp. 1-15

21. Montobbio, M., Ibíd., Pp. 151-152

22. Esta parte es un resumen, levemente modificado, de lo expuesto por Montobbio, M., Ob. Cit., pp. 153-154

23. Ibíd., p. 153

24. Ramírez, S., Adiós muchachos. Una memoria de la revolución sandinista. Madrid, Aguilar, 1999

25. Este desenlace recibió un decisivo impulso en la Cumbre de Tuxtla I, celebrada en 1991, en la que participan el presidente de México, Carlos Salinas de Gortari y los presidentes de los países centroamericanos; y en la Primera Cumbre Iberoamericana, celebrada en 1991, en Guadalajara, en la cual se consolida el consenso iberoamericano a favor de la paz en Centroamérica. Para una visión de conjunto del aporte de México al proceso de paz en Centroamérica, Ver Gordon, S., México frente a Centroamérica. México, UNAM, 1993

26. Ibíd., p. 158

27. Ver, Instituto Centroamericano de Estudios Políticos (INCEP), El proceso de paz y democratización en Centroamérica (Documentación y cronologia, 1989-1990). Guatemala, 1990

28. Gobierno de El Salvador, Frente Farabundo Martí para la Liberación Nacional (FMLN), Acuerdo de paz. Enero de 1992

29. Gobierno de Guatemala, Unión Revolucionaria Nacional Guatemalteca (URNG), Acuerdo de Paz Firme y Duradera. Diciembre de 1996

30. Para el caso salvadoreño, Cfr., Segovia, A., Transformación estructural y reforma económica en El Salvador. Guatemala, F \& G editores, 2002.

31. Para el concepto de Estado "capturado", Cfr., Evans, P., Embedded Autonomy. Princeton, NJ, Princeton University Press, 1995.

32. Cfr., Judson, F., "El ajuste y las agendas nacionales centroamericanas"..., pp.596 y ss.

33. PNUD, Estado de la región. San José, Costa Rica, 1999, p. 163.

34. En esta parte se tuvo como apoyo el "Balance regional". Proceso, No. 981, 19 de diciembre de 2001, pp. 23-28.

35. Cfr., Editorial: "Integrar lógicas contradictorias: política y economía". $E C A$, No. 576, octubre de 1996, pp. 851-864 